\title{
Governing Sex Determination in Fish: Regulatory Putsches and Ephemeral Dictators
}

\author{
J.-N. Volffa, c I. Nanda ${ }^{b} \quad$ M. Schmid ${ }^{b} \quad$ M. Schartl ${ }^{a}$ \\ ${ }^{a}$ Department of Physiological Chemistry l, and ${ }^{b}$ Institute of Human Genetics, Biocenter, University of Würzburg, \\ Würzburg, Germany; ${ }^{C}$ Institut de Génomique Fonctionnelle, Université de Lyon, Lyon, France
}

\begin{abstract}
Key Words
Dmrt1 $\cdot$ Evolution $\cdot$ Fish $\cdot$ Gonad $\cdot$ Medaka $\cdot$ Sex

determination $\cdot S R Y \cdot$ Testis $\cdot Y$ chromosome
\end{abstract}

\begin{abstract}
In contrast to the rather stable regulatory regimes established over more that 100 million years in birds and mammals, sex determination in fish might frequently undergo evolutionary changes bringing the sex-determining cascade under new master sex regulators. This phenomenon, possibly associated with the emergence of new sex chromosomes from autosomes, would explain the frequent switching between sex determination systems observed in fish. In the medaka Oryzias latipes, the Y-specific master sex-determining gene $d m r t 1 b Y$ has been formed through duplication of the autosomal gene dmrt1 onto another autosome, thus generating a new $Y$ chromosome. Dmrt1bY emerged about 10 million years ago and is restricted to several Oryzias species, indicating that the $Y$ chromosome of the medaka is evolutionarily much younger than mammalian and bird sex
\end{abstract}

Our work is supported by grants from the Deutsche Forschungsgemeinschaft (to M. Schartl and J.-N. Volff), the BioFuture programme of the Bundesministerium für Bildung und Forschung, the Association pour la Recherche contre le Cancer and the Centre National de la Recherche Scientifique (to J.-N. Volff) and the Fonds der Chemischen Industrie (to M. Schartl).

\section{KARGER}

Fax +4161306 1234

E-Mail karger@karger.ch

www.karger.com
(C) 2007 S. Karger AG, Basel

1661-5425/07/0012-0085\$23.50/0

Accessible online at:

www.karger.com/sxd chromosomes. Fertile males without $d m r t 1 b Y$ have been detected in some medaka populations, and this gene might even have been inactivated in one Oryzias species, indicating the existence of sexual regulators already able to supplant dmrt1bY. Studies on other models have confirmed that fish sex chromosomes are generally young and occurred independently in different fish lineages. The identification of new sex-determining genes in these species will shed new light on the exceptional evolutionary instability governing sex determination in fish.

Copyright $\odot 2007$ S. Karger AG, Basel

The origin and control of sex determination have fascinated philosophers and scientists over at least three thousand years [Mittwoch, 2005]. Diverse theories have been developed to explain the occurrence of males and females, particularly in human. A role of temperature has been suggested by the Greek philosophers Empedocles (ca. 494-434 BC) and Aristotle (384-322 BC), with males proposed to be 'hotter' than females. At the end of the 19 th century, the sex-determining influence of environmental factors such as temperature and nutrition was widely accepted. Finally, in the book of Genesis, alternative translation of the Hebrew 'zela' as 'side' instead of 'rib' might be suggestive of the 'bisection' of an ancestral hermaphrodite (both male and female reproductive organs in a same individual during life) to produce the gonochoristic Adam and Eve (individuals either male or 
female, with no change during life); the hypothesis of a hermaphrodite origin for man was already mentioned in myths of Persia and India more than 5000 years ago. This leads to the interesting ideas that transition between sex determination systems can occur, and that such transitions can be associated with the creation of new species.

Subsequently, the advent of genetics in the 20th century demonstrated that sex is in fact determined by chromosomes in human. Like most other mammals, Homo sapiens has a genetic sex determination system with male heterogamety, the male-determining gene SRY being carried by the Y chromosome [Graves, 2006]. The X/Y sex chromosome pair has been formed before the emergence of placental mammals at least 180 million years ago (MYA), indicating that if a 'bisection' is really at the origin of Adam and Eve gonochorism, it certainly did not affect a hermaphrodite with human appearance. Birds also have a genetic sex determination, but with female heterogamety. Both mammalian and bird sex determination systems are ancient and well conserved in their respective lineage [Marshall Graves and Shetty, 2001; Schartl, 2004a]. Interestingly, an evolutionary link between mammalian and bird sex chromosome systems might exist. The duck-billed platypus, a monotreme mammal basal to eutherians and marsupials, has five $\mathrm{Y}$ and five $\mathrm{X}$ chromosomes. One $\mathrm{X}$ chromosome is related to the human $\mathrm{X}$ chromosome, and another $\mathrm{X}$ to the bird $\mathrm{Z}$ chromosome [Grützner et al., 2004].

In contrast, almost all models of sex determination proposed during the past three thousand years apply at least partly to fish [Devlin and Nagahama, 2002; Schartl, 2004b]. Several hundreds of fish species are sequential hermaphrodites, and develop either first as a male and subsequently as a female (protandrous) or vice versa (protogynous). Synchronous hermaphrodites also exist in fish.

In gonochoristic species, all possible forms of genetic sex determination have been observed, from male and female heterogamety with or without influence of autosomal loci, to more complicated systems involving several loci but without sex chromosomes (polyfactorial sex determination), or several sex chromosomes and several pairs of sex chromosomes. In numerous species, sex determination can be influenced by the temperature and other environmental factors like the $\mathrm{pH}$ of water [Baroiller and D'Cotta, 2001], this being reminiscent of early hypotheses advanced to explain the occurrence of males and females in human. Frequently, phenotypic sex can be fully reversed by hormone treatment, a method used in aquaculture to control sexual dimorphism. Even social factors can influence sex in fish. For instance, the absence of females in the protandrous anemone fish $\mathrm{Am}$ phiprion induces sex reversal of the largest male to female [Fricke and Fricke, 1977]. Importantly, related fish species can have different mechanisms of sex determination, reflecting a frequent switching between sex determination systems during evolution [Mank et al., 2006]. Changes in sex determination might be associated with speciation events and play a role in the huge biodiversity observed in fish [Volff, 2005].

Despite this variability, there is evidence that a core of the sex determination/differentiation cascade is conserved not only between fishes but also within vertebrates [Smith et al., 1999; Zarkower, 2001; Schartl, 2004a]. For example, the expression pattern of the transcription factor Dmrt1, which is involved in the development of the male phenotype in tetrapods, is consistent with a similar role in sex determination and/or testis differentiation in both hermaphrodite and gonochoristic fish [Marchand et al., 2000; Brunner et al., 2001; He et al., 2003; Veith et al., 2003, 2006; Kobayashi et al., 2004; Winkler et al., 2004; Guo et al., 2005]. Hence, diversity of sex determination in fish might be associated with a turnover of master regulators governing a more conserved part of the sex-determining cascade.

In order to elucidate the molecular and evolutionary changes at the basis of the variability of sex determination in fish, it is necessary to identify and compare the master sex-determining genes in different fishes. Since the mammalian $S R Y$ gene is absent from fish, such studies will certainly uncover new genes able to control sex determination in vertebrates. The best models to perform such analyses are species with simple systems of genetic sex determination, if possible without influence of autosomal loci and environmental factors under experimental conditions. Sex chromosomes should be genetically well defined, with sex-linked molecular markers allowing the positional cloning of the master sex-determining gene. Ideally, tools for in vivo functional analysis should also be available, as well as genetic and genomic resources, for example genetic maps, radiation hybrid panels and genomic sequences. Unfortunately, the zebrafish Danio rerio, one of the major non-mouse models for the study of vertebrate development [Granato and Nusslein-Volhard, 1996], is a poor choice for the cloning of a master sex regulator, since neither sex-linked markers nor sex chromosomes have been identified in this species so far [Traut and Winking, 2001] and almost nothing is known about its mechanism of sex determination. Similarly, there is almost no information about sex determination in the 
Fig. 1. Major fish models and their sex determination systems. Known master sexdetermining genes are indicated. Divergence times are derived from Kumar and Hedges [1998] and Steinke et al. [2006]. The origin of pictures is given in Volff [2005].

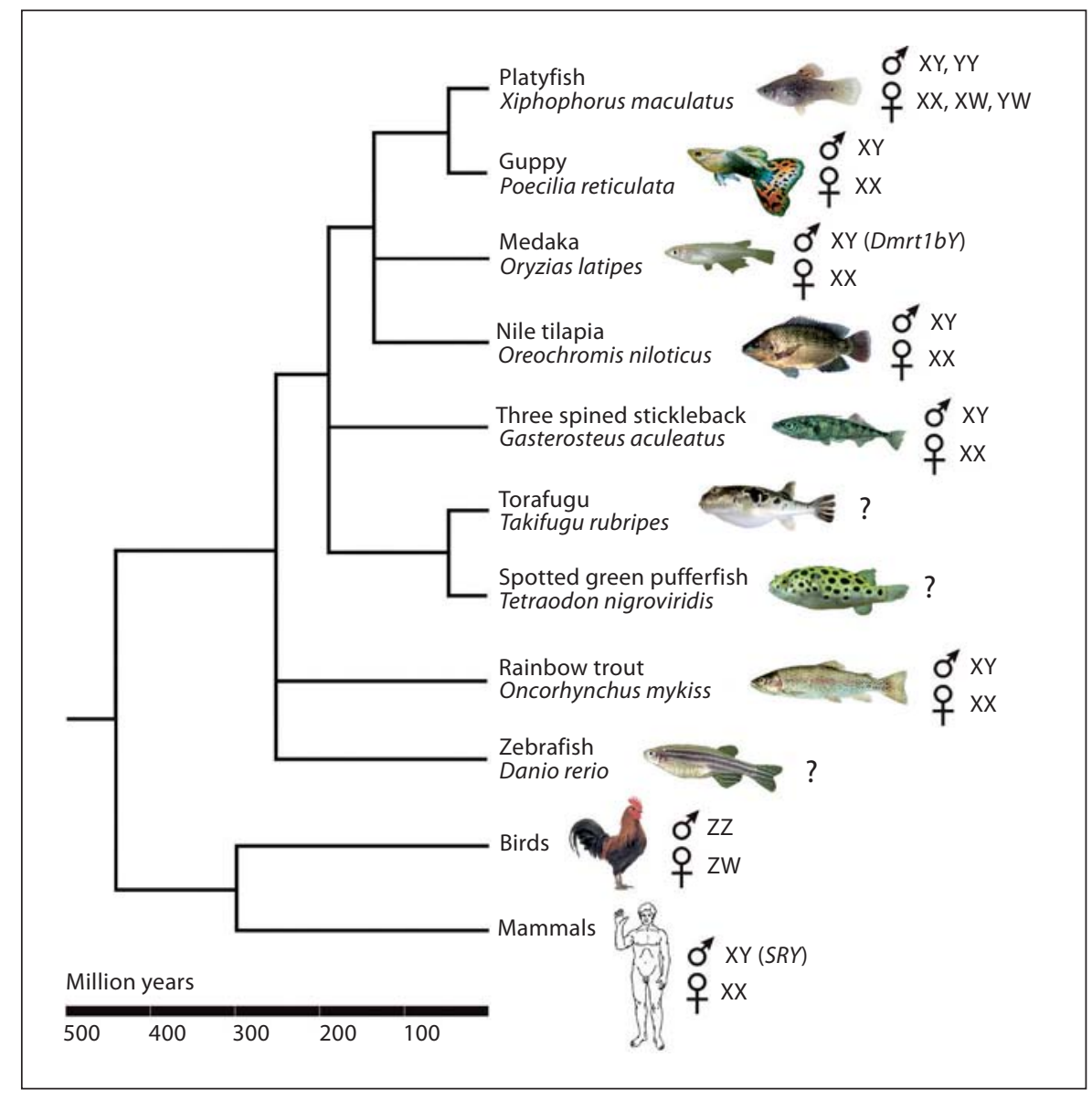

two pufferfish species with sequenced genomes, the Fugu Takifugu rubripes [Aparicio et al., 2002] and the spotted green pufferfish Tetraodon nigroviridis [Li et al., 2002; Jaillon et al., 2004; Roest-Crollius and Weissenbach, 2005], although the recent identification of a sex-linked anonymous marker sequence suggests a chromosomal sex determination mechanism with female heterogamety in T. rubripes [Cui et al., 2006]. Other models with specific advantages are more suitable to identify regulators of sex determination, and two species, the medaka Oryzias latipes and the threespine stickleback Gasterosteus aculeatus, are objects of almost completed genome sequencing projects [for reviews, Volff, 2005; Froschauer et al., 2006] (fig. 1). Some fish species like the Nile tilapia Oreochromis niloticus are studied because of their economic relevance. We review here the current knowledge available for the best studied fish models and how they contribute to our general understanding of the evolution of sex determination and sex chromosomes in fish and other organisms.

Governing Sex Determination in Fish

\section{The Medaka Oryzias latipes}

The medaka is a small oviparous freshwater fish found in Japan, Korea and eastern China (http://bioll.bio.nagoya-u.ac.jp:8000/). This fish has recently emerged as a model complementary to zebrafish particularly for the functional analysis of vertebrate development and for biomedical research. Its genome has been mapped and recently sequenced [Wittbrodt et al., 2002; Furutani-Seiki and Wittbrodt, 2004; Naruse et al., 2004].

O. latipes has a sex determination system with male heterogamety [Yamamoto, 1955]. A masculinizing effect of high temperature, leading to phenotypically normal and fertile XX males, has been noted under laboratory conditions [Sato et al., 2005]. The X and Y chromosomes are homomorphic and morphologically not distinguishable. However, medaka sex chromosomes can be visualized by fluorescent in situ hybridization (FISH) using specific molecular probes [Matsuda et al., 1998; Nanda et al., 2002]. Crossing-overs between X and Y can occur 
over almost the complete length of the sex chromosomes. However, a reduction of recombination has been observed around the sex-determining region [Matsuda et al., 1999; Kondo et al., 2001]. Suppression of recombination is classically associated with the molecular differentiation between different types of sex chromosomes [Charlesworth et al., 2005]. Such a differentiation, which over evolutionary times leads to a degeneration of Ylinked genes, is, however, not noticeable in the medaka, since YY individuals produced by steroid treatment and specific crossings are fully viable and fertile. This strongly contrasts with the lethality of YY embryos in mammals and the level of degeneration of the human Y chromosome, which carries less than 100 genes compared to approximately 1000 genes for the $\mathrm{X}$ chromosome [Skaletsky et al., 2003].

Importantly, the medaka is the first and so far only non-mammalian vertebrate for which a master sex-determining gene has been identified at the molecular level [for reviews, Volff and Schartl, 2002; Schartl, 2004b; Matsuda, 2005]. This gene, alternatively called $d m r t 1 b Y$ or $d m y$, is a Y-specific copy of the autosomal $d m r t 1$ gene located on linkage group 9 [Matsuda et al., 2002; Nanda et al., 2002]. Hence, females have only two autosomal allelic copies of $d m r t 1$; males possess, in addition, the Ylinked copy $d m r t 1 b Y$. Consistent with a role as a master sex-determining gene, natural mutations in $d m r t 1 b Y$ result in XY sex-reversed females [Matsuda et al., 2002; Otake et al., 2006] and $d m r t 1 b Y$ is the only functional gene in the Y-specific region [Kondo et al., 2006]. When medaka XY embryos are feminized by estrogen treatment, expression of $d m r t 1 b Y$ is not affected in the induced phenotypic females. This observation is consistent with a regulatory role upstream in the male cascade rather than downstream in sex differentiation [Nanda et al., 2002].

Dmrt1 belongs to a family of transcription factors related to invertebrate sexual regulators and containing a DNA binding motif called the DM domain [Zarkower, 2001; Volff et al., 2003d]. All fishes analyzed so far have an autosomal $d m r t 1$ gene with an expression pattern in testis suggestive of a conserved role in male sex determination and/or differentiation (see above). In mammals, $D M R T 1$ is also autosomal and involved in the male cascade downstream of $S R Y$ [Raymond et al., 1998]. In birds, $D M R T 1$ is present on the $\mathrm{Z}$ but not on the $\mathrm{W}$ chromosome [Nanda et al., 1999] and is expressed predominantly in the embryonic and mature male gonad [Shan et al., 2000]. Although W-linked female candidate genes have been reported [Smith and Sinclair, 2004], DMRT1 is an excellent candidate for a Z-linked male sex-determining gene in birds. Two allelic copies of DMRT1 in ZZ individuals would induce the male phenotype, ZW animals with only one copy would develop as females. Such a gene dosagedependent model of sex determination possibly applies for the medaka too - the additional Y-specific copy increasing global dmrt1 expression and inducing the male phenotype. On the other hand, autosomal dmrt1 and Ychromosomal dmrt $1 b Y$ might have diverged at the functional level after duplication. Either $d m r t 1 b Y$ has acquired a new master function (neofunctionalization), while autosomal $d m r t 1$ has kept its downstream role, or ancestral functions of the original $d m r t 1$ have been distributed between autosomal gene and Y-linked duplicate (subfunctionalization). Indeed, functional divergence has been suggested, with the involvement of non-synonymous substitutions in the coding sequences [Zhang, 2004]. In addition, $d m r t 1$ and $d m r t 1 b Y$ have different temporal patterns of expression [Nanda et al., 2002; Kobayashi et al., 2004; Winkler et al., 2004]. Dmrt1bY is expressed during embryonic development before formation of the testis. In hatchlings, expression was detected in somatic cells surrounding the germ cells. In contrast, the autosomal $d m r t 1$ is not expressed in medaka embryos and larvae. In adults, both paralogues are expressed predominantly in somatic cells of the testis. It has been proposed that $d m r t 1 b Y$ regulates primordial germ cell proliferation and differentiation during early gonadal differentiation, while $d m r t 1$ is involved in spermatogonial differentiation [Kobayashi et al., 2004].

The Y-specific region of the medaka has been generated through transchromosomal duplication of a $43-\mathrm{kb}$ segment from linkage group 9 containing $d m r t 1$ and flanked by partial sequences of the KIAA0172 and dmrt3 genes [Kondo et al., 2006]. This region, which is syntenic to human chromosome 9p, was integrated into another autosome with marked synteny to human chromosome 4q. This led to the formation of the proto-Y chromosome, the remaining member of the chromosome pair without insertion being defined as the proto-X. After integration, the $d m r t$-containing region accumulated large stretches of repetitive sequences, transposable elements and further transchromosomal duplication, which extended its size up to $258 \mathrm{~kb}$. Within this region, $d m r t 1 b Y$ is the only functional gene, all other gene candidates are degenerate. The Y-specific region is flanked by almost identical duplicated sequences with a length of $27.1 \mathrm{~kb}$, which both contain a gene of unknown function. The 27.1-kb sequence was already present on the autosome having received the integration, but as a single copy; the duplica- 
tion is assumed to have been formed during the process of insertion [Kondo et al., 2006].

Evolutionary analysis demonstrated that $d m r t 1 b Y$ is not the general master sex-determining gene in fish [Kondo et al., 2003; Volff et al., 2003b]. The duplication that led to its formation is a rather recent event that took place only 10 MYA [Kondo et al., 2004]. Dmrt1bY is present in the sister species Oryzias latipes and O. curvinotus. The Y-specific region appears to be homologous in both species [Matsuda et al., 2003; Kondo et al., 2004]. In the closely related species $O$. luzonensis, two copies of $d m r t 1$ have been identified: the ubiquitous autosomal $d m r t 1$ gene as well as a pseudogenic copy possibly corresponding to a degenerate $d m r t 1 b Y$ [Kondo et al., 2004]. In contrast, $d m r t 1 b Y$ is clearly absent from more distant Oryzias species like O. celebensis and O. mekongensis as well as from other fish genera [Kondo et al., 2003]. Hence, $d m r t 1 b Y$ has been formed during evolution of the Oryzias lineage. There is no evidence so far from any fish species that $d m r t 1$ itself might serve as master sex-determining gene.

Even if a functional $d m r t 1 b Y$ has been maintained over 10 millions of years on the Y chromosome of several Oryzias species, this gene failed to reach evolutionary stability through the development of an indispensable function in sex determination. Males with normal phenotype and uncompromised fertility but lacking dmrt1bY ('XX males' according to the classical sex chromosome system) have been detected in several laboratory strains of Northern and Southern medaka at frequencies up to $10 \%$ [Nanda et al., 2003] as well as in nature [Shinomiya et al., 2004]. This indicates that $d m r t 1 b Y$ is dispensable for the development of the male phenotype under certain conditions in the medaka. In addition, $d m r t 1 b Y$ has possibly been inactivated in O. luzonensis [Kondo et al., 2004], a species with an XY sex determination system closely related to the medaka [Hamaguchi et al., 2004]. Hence, it is questionable whether the dmrt1bY-dependent sex determination will be able to survive over long periods of evolution as observed for $S R Y$ in mammals. An autosomal factor has been mapped that is responsible for XX female-tomale sex reversal [Shinomiya et al., 2003]. This locus may be an emerging sex determinator that is able to replace dmrt1bY. In another case, a strain of medaka with a ZZ/ $\mathrm{ZW}$ type of sex determination has been derived from a naturally occurring mutation [Shinomiya et al., 2002]. It will be particularly interesting to determine if $d m r t 1 b Y$ has been replaced in sex reversed or ZW medaka by the ancestral sexual regulator that it supplanted 10 million years ago or by a new master gene.

Governing Sex Determination in Fish

\section{The Platyfish Xiphophorus maculatus and Other Poeciliids}

Xiphophorus is a freshwater fish genus living in eastern drainages of Mexico, Guatemala, Belize and Honduras, with most of the described species living in Mexico (http://www.xiphophorus.org). Xiphophorus species are classified into three groups, the northern swordtails, the southern swordtails and the platyfishes. Xiphophorus belongs to Poeciliidae, a fish family well known to scientists, but also fish hobbyists. The family includes the guppy Poecilia reticulata, which is commonly used for ecological and evolutionary studies. Xiphophorus itself is a well-established model for cancer research, since melanoma can be induced in these fishes through interspecific crossing [Meierjohann et al., 2004; Meierjohann and Schartl, 2006]. Genetic maps are available for Xiphophorus [Kazianis et al., 2004], making the identification and isolation of genes for various traits, including sex determination and differentiation, possible.

The best studied Xiphophorus species with respect to sex determination is the platyfish $X$. maculatus [Kallman, 1984]. This species has a peculiar sex-determining system with three sex chromosomes: X, Y and W. Males can be either XY or YY, females XX, XW or YW. WW females can also be obtained under laboratory conditions. Platyfish strains with male heterogamety (XX/XY) or female heterogamety (YW/YY) with apparent absence of autosomal and environmental influences are available for comparative studies.

Several models have been proposed to explain the rather unusual sex determination of the platyfish. The first postulates that male-determining genes are present not only on the $\mathrm{Y}$ but also on the $\mathrm{X}$ and $\mathrm{W}$ chromosomes [Kallman, 1984]. In this model only the Y chromosomal allele is active, since autosomal repressors suppress the $\mathrm{X}$ and $\mathrm{W}$ alleles. In addition, the $\mathrm{W}$ chromosome might carry a suppressor for the Y-chromosomal allele, thus explaining the female phenotype of YW individuals.

In a second model, platyfish sex determination has been proposed to be gene dosage-dependent [Volff and Schartl, 2001]. A male sex-determining gene might be present with different copy numbers on the Y (2 copies), the X (1 copy) and the W (no copy). The higher copy number and expression of the male regulator in XY and YY genotypes would lead to the male phenotype.

The viability of both YY males and WW females shows that platyfish $\mathrm{W}$ and $\mathrm{Y}$ chromosomes are not extensively degenerate. Accordingly, $\mathrm{X} / \mathrm{Y}$ recombination can take place over almost the entire length of the chromosomes.

Sex Dev 2007;1:85-99 
At the cytogenetic level, no obvious morphological differences can be observed between different types of sex chromosomes. Differentiation between $\mathrm{X}$ and $\mathrm{Y}$ was detected neither through synaptonemal complex analysis (the analysis of the pairing of meiotic chromosomes), nor through comparative genomic hybridization [Traut and Winking, 2001]. Platyfish sex chromosomes, hardly distinguishable from the larger chromosomes in the metaphase spread, can be identified by FISH using repeated sequences or bacterial artificial chromosomes (BACs) as probes [Nanda et al., 2000; Schultheis et al., 2006]. Such experiments showed that the sex-determining region of the platyfish is located in the subtelomeric region of the sex chromosomes [Nanda et al., 2000]. In addition, accumulation of a repeat called XIR was observed by FISH on the $\mathrm{Y}$ but not on the $\mathrm{X}$ chromosome in one platyfish population. This recent amplification possibly corresponds to an early step of molecular differentiation between X and Y [Nanda et al., 2000].

Genetic analysis has demonstrated that several gene loci are closely linked $(<1.0 \mathrm{cM})$ to the sex-determining locus $S D$ of X. maculatus [Kallman, 1984; Volff and Schartl, 2001, 2002; Schultheis et al., 2006 and references therein]. Two of these loci, Tu for 'Tumor' and Mdl for 'Macromelanophore-determining locus', are involved in the formation of melanoma in interspecific hybrids of $X i$ phophorus. Tu is the oncogenic locus derepressed in fishes developing cancer, and $M d l$ is required for the formation of macromelanophores, the large melanin-producing pigment cells that are the progenitors of melanoma cells. $M d l$ and Tu determine the pathophysiological properties of melanoma. Other $S D$-linked loci include the redyellow locus $R Y$, which is responsible for red, brown, orange and yellow pigmentation patterns in the iris, on the body and in the fins, and the puberty locus $P$, a polymorphic locus determining the onset of sexual maturity in Xiphophorus.

Several molecular markers are available for the sex chromosomes of the platyfish, and the sex-determining region has been mapped to linkage group 24 [Kazianis et al., 2004; Woolcock et al., 2006]. Importantly, the Xiphophorus melanoma receptor tyrosine kinase oncogene $X m r k$, which corresponds to the tumor locus Tu, is closely linked to the sex-determining locus [Wittbrodt et al., 1989]. This oncogene has been formed by duplication and subsequent mutation of the gene egfrb encoding an epidermal growth factor receptor, which is also sex-chromosomal [Adam et al., 1993]. Making use of these different sex chromosomal markers, BAC contigs have been constructed for the $\mathrm{X}$ and $\mathrm{Y}$ chromosomes and are currently being sequenced [Froschauer et al., 2002; Schultheis et al., 2006]. This positional cloning approach should allow the identification of candidates for the sex-determining gene as well as for other sex chromosomal loci. Neither $d m r t 1$ nor other $d m r t$ genes are apparently located in the sex chromosomal contigs, suggesting that studies in platyfish will lead to the identification of a novel type of master sexual regulator in fish [Veith et al., 2003].

Initial partial sequencing of BAC contigs revealed sequences with significant similarity to known genes, particularly from other vertebrates [Schultheis et al., 2006]. However, none of them has an expression pattern or a function in other organisms suggestive of a role as master sex-determining gene. Syntenies were observed with zebrafish chromosomes 2 and 12, human chromosomes 2 , 5,7 and 18 , chicken chromosomes 2 and 3 as well as with unmapped genomic scaffolds from several sequenced fish genomes [Schultheis et al., 2006]. No synteny was detected with sex chromosomes from other fish species, suggesting independent origin of the gonosomes.

Strikingly, numerous gene candidates have been duplicated or even amplified in the sex-determining region of the $\mathrm{X}$ and the $\mathrm{Y}$ chromosomes [Volff et al., 2003c; Schultheis et al., 2006]. Subsequently, most duplicated copies have been inactivated by partial deletions and other types of mutations and evolved as pseudogenes. In addition, numerous repetitive sequences, particularly retrotransposable elements, have been identified in the sexdetermining region [Volff et al., 2003c; Schultheis et al., 2006; Zhou et al., 2006]. Some of these transposable elements are still active [Schartl et al., 1999]. Taken together, these observations indicate that the sex-determining region of the platyfish is a hot-spot for duplications, amplifications, transpositions and other kinds of rearrangements. This plasticity might be related to the variability of sex determination and other sex-linked traits observed in Xiphophorus and other fishes. Alternatively, the high density of repetitive DNA and transposable elements could be the result of the specific evolution of sex chromosomes, because suppressed recombination causes the accumulation of repetitive sequences [Charlesworth et al., 1986, 1994].

Beside $X$. maculatus, sex determination has been well studied from the genetic point of view in other Xiphophorus species as well as in other poeciliids [Volff and Schartl, 2001; Schartl, 2004b and references therein]. Several Xiphophorus species including $X$. variatus, $X$. $x i$ phidium, $X$. nezahualcoyotl, $X$. milleri and $X$. nigrensis have basically an XX/XY system, with occasional influence of autosomal factors. In the green swordtail X. hel- 
lerii, both polyfactorial and ZW/ZZ sex determination systems have been described [Woolcock et al., 2006]. Finally, $X$. alvazeri has a mechanism with female heterogamety.

In the guppy Poecilia reticulata, a species with XY male heterogamety, genes encoding highly polymorphic color patterns and fin shapes are Y-, X- or X/Y-linked [Lindholm and Breden, 2002]. Examples of Y-specific loci are $\mathrm{Ma}$ (Maculatus, pigmentation), Ar (Armatus, pigmentation and caudal fin) and $\mathrm{Pa}$ (Pauper, pigmentation) [Kirpichnikov, 1981]. In contrast to medaka and platyfish, YY males homozygous with respect to these Y chromosomal loci are generally not viable, suggesting Y chromosome degeneration. Interestingly, YY males with combinations of different $\mathrm{Y}$ chromosomes, for example $\mathrm{Y}_{\mathrm{Ma}} \mathrm{Y}_{\mathrm{Ar}}, \mathrm{Y}_{\mathrm{Ma}} \mathrm{Y}_{\mathrm{Pa}}$ or $\mathrm{Y}_{\mathrm{Pa}} \mathrm{Y}_{\mathrm{Ar}}$, are viable and fertile [Kirpichnikov, 1981], pointing to a differential degeneration in different Y chromosomes. Guppy Y chromosomes have been cytologically well characterized through comparative genomic hybridization and synaptonemal complex analysis of pachytene spermatocytes. Although both X and $\mathrm{Y}$ are of the same size and morphology, the $\mathrm{Y}$ chromosome contains a short distal differentiated region [Traut and Winking, 2001].

The mollies Poecilia velifera, P. latipinna and P. sphenops (black molly) also essentially have a system with male heterogamety. However, female heterogamety has been observed in $P$. sphenops too, with partial heterochromatinization of the $\mathrm{W}$ chromosome [Haaf and Schmid, 1984].

Both types of heterogamety have been described in the two subspecies of mosquito fish Gambusia affinis [Volff and Schartl, 2001 and references therein]. In G. affinis holbrooki, the subspecies with male heterogamety, a chromosome polymorphism is apparent due to the presence of a locus for black pigmentation on a certain $\mathrm{Y}$ chromosome lineage. Autosomal influences have been reported. Early cytogenetic analyses detected a large heteromorphic sex chromosome pair in females (ZW) in all populations of $G$. affinis affinis but not in the other subspecies G. affinis holbrooki [Black and Howell, 1979].

Poeciliids are a relatively young group of teleosts. The diversification of the different genera and origin of the extant species has happened in a timeframe of 5 to 30 MYA. It is therefore reasonable to assume that some of the sex determination systems are younger than a few million years. It appears not very likely that in all species with different sex determination systems the same master sex-determining gene operates but with a different effect on sex development. This would mean that a gene in one species directs female and in the other male gonad formation. It is more likely that the diversity of sex determination mechanisms reflects the action of different master sex regulators. Comparative study of the plethora of genetic sex determination systems observed in $\mathrm{Xi}$ phophorus and other poeciliids will allow, based on detailed molecular studies in the platyfish, to better understand the transition between sex-determining systems in fish.

\section{The Threespine Stickleback Gasterosteus aculeatus}

The threespine stickleback, a small fish widely distributed throughout the Northern hemisphere, is an outstanding model for the study of evolutionary developmental biology in vertebrates [Peichel, 2005]. A first sequence assembly of the genome of G. aculeatus is available (http://ensembl.genome.tugraz.at/Gasterosteus_aculeatus/index.html).

The threespine stickleback has a genetic sex determination system with male heterogamety [Peichel et al., 2004]. The $X$ and $Y$ chromosomes are not distinguishable cytogenetically, indicating that they are at an initial step of molecular differentiation. Recombination rates are reduced around the sex-determining locus. Sequencing of $\mathrm{BAC}$ clones covering $250 \mathrm{~kb}$ of the $\mathrm{X}$ and $\mathrm{Y}$ chromosomes identified genes encoding among others an NAPD-dependent isocitrate dehydrogenase (Idh) and a zinc finger protein (Znf) [Peichel et al., 2004]. Synteny was observed with human chromosome 15q24-q26, but not with the sex chromosomes of Xiphophorus, which show no conserved synteny with human chromosome 15 . In medaka the region of the sex chromosome containing the maledetermining gene is syntenic to human chromosome 4 [Kondo et al., 2006]. This strongly suggests that these fish sex chromosomes have arisen independently from different chromosomes of an ancestral karyotype.

All sex chromosomal genes identified so far in stickleback are located on both the $\mathrm{X}$ and $\mathrm{Y}$ chromosomes. Despite this apparent conservation of gene content, important sequence differences were observed between both types of gonosomes. This was particularly due to the preferential accumulation of transposable elements and other repeated sequences as well as to the presence of multiple local duplications on the Y chromosome [Peichel et al., 2004].

Both Idh and Znf genes were found to be sex chromosomal in five natural populations of G. aculeatus. In contrast, these genes are apparently autosomal in the sister 
species $G$. wheatlandi. Taken together, these results suggest a rather recent evolutionary origin for the sex chromosomes of the threespine stickleback, which might have been formed between 2 and 10 MYA [Peichel et al., 2004].

\section{Salmonids}

The family Salmonidae includes economically important fish species from the Northern hemisphere. Some salmonids are pure freshwater species, others are anadromous - they are born in freshwater streams or lakes, spend their adult phase in the ocean, and return to their natal waters to spawn. Comparative linkage maps as well as physical BAC maps are available for some species, and large-scale sequencing projects are underway [Danzmann et al., 2005; Ng et al., 2005; Volff, 2005; Gharbi et al., 2006].

Salmonid species including the rainbow trout $\mathrm{On}$ corhynchus mykiss, the Arctic charr Salvelinus alpinus, the brown trout Salmo trutta and the Atlantic salmon Salmo salar have a genetic sex determination with XY male heterogamety [Woram et al., 2003]. Influence of autosomal loci can occasionally occur [Quillet et al., 2002]. Sex chromosomal markers have been identified for several species, and sex chromosomes have been extensively studied cytogenetically, particularly by FISH using BAC clones, repetitive sequences or degenerate oligonucleotide-primed (DOP) PCR-amplified sex chromosomal DNA as probes [Allendorf et al., 1994; Forbes et al., 1994; Reed et al., 1995; Devlin et al., 2001; Iturra et al., 2001; Stein et al., 2001; Felip et al., 2004; Artieri et al., 2006]. Heteromorphic sex chromosomes are observed in some species [Thorgaard, 1977; Phillips and Rab, 2001]. However, sex chromosomes in salmonids are generally considered to be at an early stage of differentiation. This is confirmed by the viability and fertility of YY males.

The sex-determining region is telomeric in brown trout, Atlantic salmon, and Arctic charr but apparently at an intercalary position in the rainbow trout [Woram et al., 2003]. In each species, the Y-specific region is very short. Strikingly, the major male sex-determining gene is located on different linkage groups in these four salmonids, indicating that different $\mathrm{Y}$ chromosomes have evolved in each species [Phillips et al., 2001, 2005; Woram et al., 2003]. This contrasts with the extensive interspecific synteny observed for regions not involved in sex determination. Such an absence of conservation of sex linkage between species can be explained by (i) the trans- location of a small chromosome arm containing the sexdetermining gene onto an autosome, this leading to the formation of a new $\mathrm{Y}$ chromosome, (ii) the transposition of the sex-determining gene onto an autosome, and (iii) the activation of unlinked master sex-determining genes in different species [Woram et al., 2003]. Detailed molecular analysis of Y-specific regions in different species will allow deciding which of these scenarios is the basis of sex chromosome switching in salmonids.

\section{The Tilapias Oreochromis niloticus and Oreochromis aureus}

The Nile tilapia O. niloticus is a cichlid of African origin. This fish is of high economical importance, with allmale stocks being generally used in the aquaculture. Both genetic linkage map and BAC-based physical map are available for tilapia [Katagiri et al., 2005; Lee et al., 2005], and large scale genomic sequencing is planned (http:// hcgs.unh.edu/cichlid/).

O. niloticus has primarily an XY sex-determining system, with occasional influence of autosomal loci and masculinizing effect of high temperature [Mair et al., 1991; Baroiller et al., 1995; D’Cotta et al., 2001; Griffin et al., 2002]. Sex chromosomes are not morphologically identifiable and $\mathrm{YY}$ individuals are viable and fertile, indicating a poor degree of differentiation between $\mathrm{X}$ and Y. Synaptonemal complex analysis identified pairing anomalies in a terminal portion of the largest pair of bivalents (chromosome 1) in XY males but neither in XX females nor in YY males, suggesting that this pair corresponds to the sex chromosomes [Foresti et al., 1993; Carrasco et al., 1999]. This reduced pairing has been proposed to be linked to subtle differences in the amount of heterochromatin in the sex-determining region of the $\mathrm{X}$ and Y chromosomes [Griffin et al., 2002].

Several microsatellites and amplified fragment length polymorphism (AFLP) markers linked to the sex chromosomes have been identified [Lee et al., 2003; Ezaz et al., 2004]. Their sex linkage is dependent on the family analyzed, suggesting the differential influence of additional genetic and environmental sex-determining factors. In FISH experiments, BAC clones containing sexlinked AFLP markers hybridized to the long arm of chromosome 1 [Ezaz et al., 2004]. This confirmed the results of synaptonemal complex analysis and strongly supports the idea that the chromosome 1 pair corresponds to the sex chromosomes. The sex-linked markers will be very useful to identify the male sex-determining 
gene on linkage group/chromosome 1, for example through the isolation and sequencing of sex chromosomal BAC clones.

FISH probes for the sex chromosomes, largely derived from transposable elements, have been generated through amplification by DOP-PCR after microdissection of chromosome 1 from XX and YY genotypes. Comparative hybridization of X and $Y$ chromosome-derived probes revealed modest signal differences between $\mathrm{X}$ and $\mathrm{Y}$, suggesting an early stage of differentiation [Harvey et al., 2002]. This initiation of differentiation might involve the differential accumulation of transposable elements [Harvey et al., 2003].

A related species, the blue tilapia Oreochromis aureus, has a major sex-determining system with ZW female heterogamety. The major female $\mathrm{W}$ locus has been mapped onto linkage group 3 [Lee et al., 2004]. In addition, a male-determining locus has been localized on linkage group 1, which is homeologous to the $\mathrm{X} / \mathrm{Y}$ chromosomes in O. niloticus. Hence, sex determination in the blue tilapia might be determined by epistatic interactions between a dominant male repressor on linkage group 3 and a male inducer on linkage group 1 [Lee et al., 2004]. Markers linked to sex determination on linkage groups 1 and 3 have also been identified in an F2 hybrid cross between O. aureus and O. mossambicus [Cnaani et al., 2004]. Interestingly, these results are concordant with those obtained through synaptonemal complex analysis, which also suggested that $O$. aureus has two separate pairs of sex chromosomes. Two distinct regions of restricted pairing have been observed, one in a subterminal region of chromosome 1 (corresponding to linkage 1) and the second in a small bivalent pair [Campos-Ramos et al., 2001]. Further comparative analysis between Nile and blue tilapias will certainly provide interesting insights into the mechanisms driving the transition between sex determination systems in fish.

\section{Comparative 'Sexomics' in Vertebrates: Fish versus Mammals}

General rules concerning the evolution of sex determination can be derived from parallel studies of sex chromosomes in different teleost species, which clearly demarcate fish from mammals. In contrast to mammalian sex chromosomes, most fish chromosomes are evolutionarily young and at very early stages of differentiation [Charlesworth, 2004]. No important degeneration is generally observed for the heterozygous chromosome. How-

Governing Sex Determination in Fish ever, only in a few instances characteristic differentiation has been detected. For example, among the 40 analyzed species of the neotropical fish Leporinus (Anastomidae), 7 species have morphologically well-differentiated sex chromosomes (ZZ/ZW), generally with a larger heterochromatic W chromosome [Koehler et al., 1997]. On the other hand, some common general patterns have also been detected between fish and mammals.

Suppression of recombination in the sex-determining region, one of the early steps toward the differentiation of sex chromosomes, has been reported for several fish species. Such observations are consistent with evolutionary patterns observed in other animals with either male or female heterogamety [Charlesworth et al., 2005]. In the medaka, the non-recombining region of the $\mathrm{Y}$ chromosome has been formed directly through integration of a segment originating from another chromosome and containing the new master sex-determining gene; this region is present on the new $\mathrm{Y}$ but not on the new $\mathrm{X}$ chromosome [Nanda et al., 2002]. In other fish models, the lack of sequence information concerning the sex-determining region does not allow to determine the mechanisms suppressing recombination and to test for example if inversions are involved, as observed in other organisms [Charlesworth et al., 2005].

Suppression of recombination generally keeps together genes with functions advantageous for one sex (for example genes beneficial for male functions on the Y chromosome) and avoids their transfer to the other type of sex chromosomes, where they might have negative effects on the opposite sex (sexually antagonistic genes). Accordingly, the mammalian $\mathrm{Y}$ chromosome is specialized for genes with male functions: numerous testis-specific genes involved in male fertility are linked to the male-inducing gene $S R Y$ in the Y chromosome-specific region [Skaletsky et al., 2003; Graves, 2006]. Deletions of these genes located in the so-called AZF (azoospermia factor) regions lead to severe oligozoospermia and azoospermia and consequently to infertility [McElreavey et al., 2006]. The Y-specific region containing these 'male' genes does not recombine with the mammalian $\mathrm{X}$ chromosome.

In fish, spontaneous or hormonally sex-reversed XX males are generally fully fertile. Hence, some male fertility genes are located either on the X chromosome or on autosomes, indicating that the reproductive malespecific specialization of the $\mathrm{Y}$ chromosome is not so pronounced in fish as in mammals. On the other hand, loci encoding sexually selected traits attractive for females such as color patterns, size and shape of caudal fins or courtship behavior are linked to male sex-deter- 
mining genes on $\mathrm{Y}$ chromosomes in guppies and other species [Lindholm and Breden, 2002]. Since these loci are advantageous for male reproduction but might have negative effects in females, suppression of recombination might emerge to conserve their genetic linkage to the male master regulator. Some of these traits are unrelated to sexual differentiation and therefore candidates for antagonistic traits in fish [Lindholm and Breden, 2002]. Conversely, the expression of other traits is androgen-dependent. Therefore, these traits can hardly be considered as sexually antagonistic, since their expression will be male-specific independently of their genomic location.

One classical consequence of the suppression of recombination is the genetic degeneration of the heterozygous chromosome ( $\mathrm{Y}$ in male heterogamety and $\mathrm{W}$ in female heterogamety) [Charlesworth et al., 2005]. This is reflected by the situation observed in humans and other mammals, where $\mathrm{X}$ and $\mathrm{Y}$ chromosomes are extremely divergent and morphologically differentiated. The human $\mathrm{Y}$ chromosome is mostly heterochromatic and much shorter that the X chromosome. X/Y homologous pairing occurs only between two restricted pseudoautosomal regions located at the extremities of the chromosomes. In human, over $90 \%$ of X-chromosomal genes do not have any counterpart on the Y chromosome [Skaletsky et al., 2003; Graves, 2006]. Consequently, the YY genotype is not compatible with life in mammals. Conversely, YY and WW genotypes are viable in most fish species. This indicates that the gene content of the $\mathrm{Y}$ and $\mathrm{W}$ chromosome is very similar to that of their $\mathrm{X}$ and $\mathrm{Z}$ counterparts. Generally, fish sex chromosomes are not distinguishable at the morphological level. However, candidate sex chromosomes can be identified through anomalies of pairing during meiosis (synaptonemal complex analysis) or FISH.

Taken together, these observations indicate that most fish sex chromosomes are at very early stages of differentiation compared to mammalian sex chromosomes, suggesting that they have been formed more recently. Indeed, evolutionary analyses in medaka and stickleback showed that the sex chromosomes in these species are only 10 million years old or even younger [Kondo et al., 2004; Peichel et al., 2004]. Sex chromosomes are different in several species of salmonids, also suggesting recent origin [Woram et al., 2003]. In addition, there is no evidence of synteny between the sex chromosomes of the most studied model fish species. Hence, the picture emerging is the repeated creation of new sex chromosomes during evolution in fish, possibly in association with the formation of new sexual master regulators. As shown in the medaka, new sex chromosomes in fish apparently emerge from autosomes, according to early models of evolution [Muller, 1914, 1918; Ohno, 1967]. In contrast, the same XY sex determination system, the same sex chromosomes and the same sex-determining gene have been conserved over about 200 million years of evolution in marsupials and in almost all placental mammals, with an extreme degree of degeneration and specialization of the $\mathrm{Y}$ chromosome reached in numerous species [Graves, 2006].

Generally, sex chromosomes in fish, and particularly Y chromosomes, are rich in transposable elements and other types of repeated sequences [Nanda et al., 2000; Harvey et al., 2003; Volff et al., 2003c; Peichel et al., 2004; Kondo et al., 2006]. Such a phenomenon is common to heterozygous sex chromosomes in mammals and other organisms, possibly as a consequence of the suppression of recombination [Charlesworth et al., 1986; Bachtrog, 2003; Gvozdev et al., 2005; Steinemann and Steinemann, 2005]. Differential accumulation of transposable elements, which are active in fish, might play a role in the differentiation of sex chromosomes [Harvey et al., 2003; Volff et al., 2003a, c].

Furthermore, intrachromosomal segmental duplications have frequently been detected on fish sex chromosomes [Volff et al., 2003c; Peichel et al., 2004; Kondo et al., 2006], as observed on mammalian Y chromosomes [Samonte and Eichler, 2002; Skaletsky et al., 2003]. As proposed for duplicated genes within palindromes on the primate Y chromosome [Rozen et al., 2003; Skaletsky et al., 2003], duplicated sex-linked genes on fish sex chromosomes may correspond to 'backups' used to repair mutated genes, for example by gene conversion. This might be particularly important to avoid haploinsufficiency for genes located in the non-recombining region of the $\mathrm{Y}$ and $\mathrm{W}$ chromosomes if no dosage compensation mechanism is available (see below).

In the platyfish as well as in some other fish species, insertions of transposable elements, duplications and other types of rearrangements are not specific for the $\mathrm{Y}$ but are also found on the X chromosome [Volff et al., 2003c]. This does not correspond to the pattern expected if these rearrangements solely result from chromosome degeneration and specialization. One possibility is that these rearrangements have been transferred from the $\mathrm{Y}$ to the $\mathrm{X}$ chromosome through residual $\mathrm{X} / \mathrm{Y}$ recombination. Alternatively, the instability of such regions might predate their recruitment as sex-determining regions. Autosomal parts of genomes with higher plasticity and/ 
or lower density of essential genes might be predestined to become new sex-determining regions because of the higher probability to receive or evolve new sex-determining and sex-specific genes and subsequently to generate a non-recombining region through rearrangements. Strikingly, the sex-determining region of numerous fishes is (sub)telomeric [Nanda et al., 2000; Woram et al., 2003]. Evidence from many organisms indicates that chromosome ends are generally unstable and might correspond to regions of accelerated evolution [Pryde et al., 1997; Volff et al., 2003c].

\section{What Is the Evolutionary Basis of Sex Determination Variability in Fish?}

Why is sex determination so diverse in fish compared to mammals and birds? It has been suggested that fish might have some developmental and genomic predisposing peculiarities, including a flexibility of differentiation of male and female gonads from a same precursor tissue, as well as a high number of gene duplicates and an important genomic plasticity [Volff, 2005; Froschauer et al., 2006; Mank et al., 2006]. However, the most important but so far largely unanswered question concerns the selection pressures behind the diversity of sex determination. Does the frequent switching between sex-determining systems provide any advantage to fish, or is it only a consequence of a peculiar mode of evolution? Particularly interesting is the fact that most $\mathrm{Y}$ and $\mathrm{W}$ sex chromosomes are poorly or not degenerate in fish despite an apparent suppression of recombination in the sex-determining region. Are fish sex chromosomes so poorly differentiated because they did not have time to degenerate, or because degenerated chromosomes are not viable in fish?

The ability of changing the control of sex determination might have been selected to respond to external sex ratio distortions. This might be important as an adaptation to environmental changes affecting the temperature or the $\mathrm{pH}$ of the water, or for the colonization of a new biotope with different environmental parameters. Imagine a fish species like the Nile tilapia Oreochromis niloticus, with genetic sex determination at lower temperature but strong masculinizing effect of higher temperature. An increase of water temperature in the natural habitat might induce a sex ratio deviation toward males, thus compromising the survival of the population. Abolishment of the temperature-dependent regulation through modification of the existing sex determination system or creation of a new sex-determining gene might restore the balance between males and females.

Furthermore, parasitic sex ratio distorters have been described in animals. In arthropods and nematodes, the intracellular bacterium Wolbachia, which is transmitted only by females through the egg cytoplasm, is able to interact with the sex determination system of its host in order to promote its own spread. Wolbachia can, among others, feminize or even kill males, this leading to strong female-biased sex ratio distortions [Charlat et al., 2003]. The ability to develop a new sex determination system escaping the control of the parasite would be of advantage. Hence, the diversity of sex determination observed in insects might be linked to the race against such sexmanipulating agents. Whether such parasitic sex ratio distorters exist in fish is unknown at the moment.

On the other hand, the necessity to develop new controls of sex determination might be linked to peculiar facets of sex chromosome evolution in fish. It is generally accepted that one important consequence of the suppression of recombination is the erosion and degeneration of the $\mathrm{Y}$ and $\mathrm{W}$ chromosomes [Charlesworth et al., 2005]. Consequently, mechanisms must be developed to compensate for the imbalance in gene dosage created by gene loss in the heterogametic sex. Dosage compensation equalizes $\mathrm{X} / \mathrm{Z}$ gene dosage between males and females but also balances expression between the $\mathrm{X} / \mathrm{Z}$ chromosomes and the autosomes. This has been achieved using different strategies in animals, for example male-specific upregulation of X-chromosomal genes in Drosophila or general upregulation followed by female-specific random inactivation of one $\mathrm{X}$ chromosome in mammals [Larsson and Meller, 2006]. To date, no evidence has been provided that dosage compensation mechanisms exist for fish sex chromosomes [Devlin and Nagahama, 2002]. The absence of such a mechanism might lead to haploinsufficiency for dose-sensitive sex chromosomal genes, with potential reduction of fitness in the heterogametic sex (fig. 2). Evolution of new sex chromosomes would allow the restoration of the diploid set of genes and the return of the ancient sex chromosomes to an autosomal status. Hence, new sex chromosomes and new sex determination systems may be created in fish to avoid the extinction of the heterogametic sex and consequently of the population or the species. However, dosage compensation has not been proven to be absent in fish, and these animals might be generally less sensitive to the gene dosage problem than mammals, as suggested by the frequent occurrence of healthy triploids, tetraploids and diploid/triploid mosaics. 


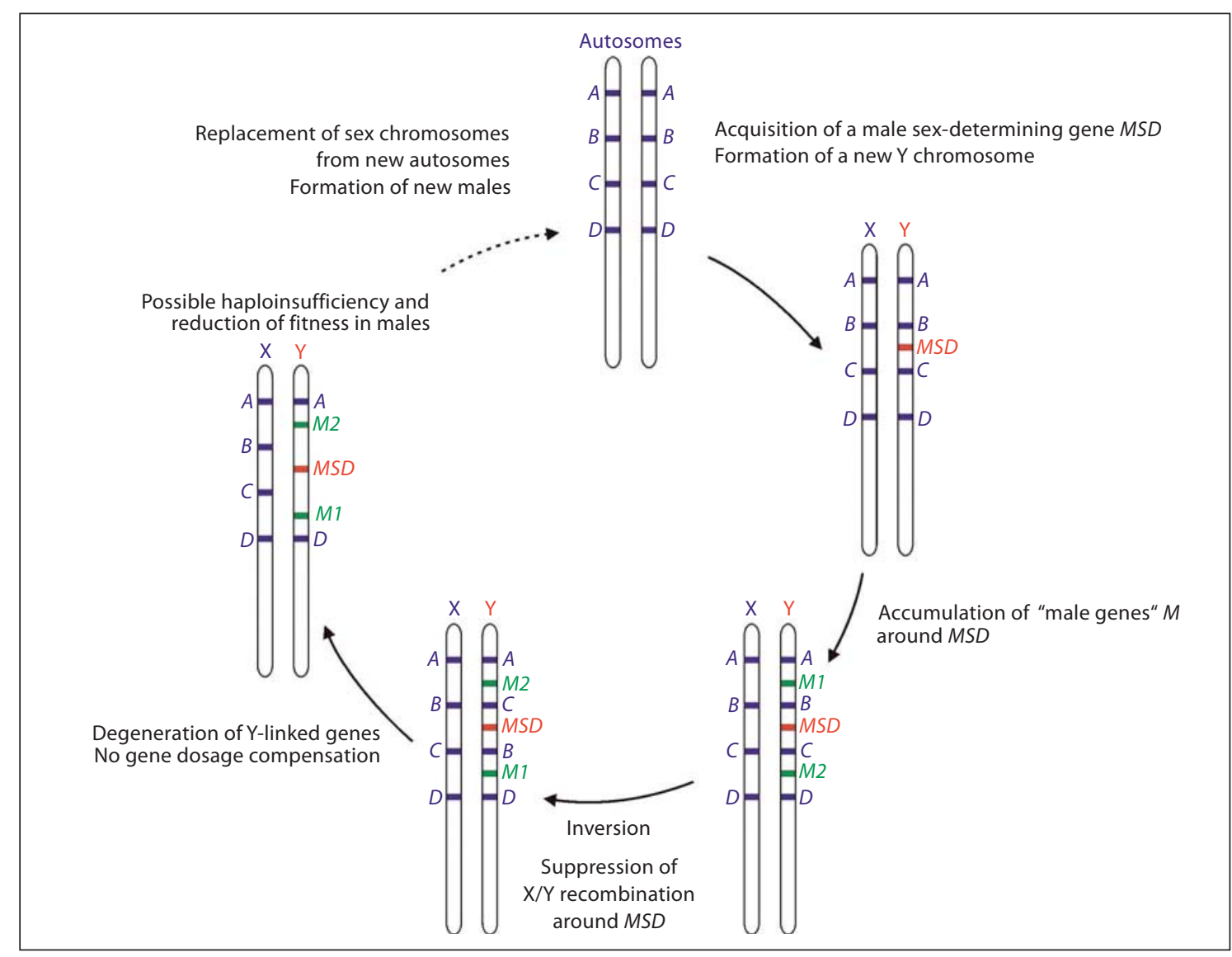

Fig. 2. Evolutionary scenario for the repeated formation of sex chromosomes in fish. One autosome acquires a dominant male (or female) sex-determining gene MSD and becomes the new $\mathrm{Y}$ (or the new W) chromosome, the remaining chromosome of the pair without $M S D$ is the new $\mathrm{X}$ (or the new $\mathrm{Z}$ ) chromosome. $M S D$ can be either gained through transfer from another chromosome or activated through mutation of a pre-existing gene on the ancestral autosome. Genes advantageous for males and possibly deleterious for females might accumulate at the vicinity of MSD. In order to maintain their association in males, meiotic recombination is suppressed around $M S D$, for example through inversions [Charlesworth et al., 2005]. This would lead to genetic isolation

\section{Conclusion}

The sex determination/differentiation cascade in fish might be compared to a politically unstable country, with a core (the population), a master regulator at the top of the hierarchy (the dictator) followed by several downstream regulatory genes between master gene and conserved core (the ministers). If an evolutionary putsch occurs, the dictator might be eliminated and replaced by a new dictator of independent origin, or the dictator might be replaced by one of his 'downstream' ministers. This of the $M S D$-linked region and to degeneration of associated genes on the Y. In absence of dosage compensation, for example through increase of transcription of $\mathrm{X}$ chromosomal genes in males, such a situation might lead to haploinsufficiency for certain genes, with possible negative effects in the heterogametic sex. New males starting a new cycle with a new non-degenerated $\mathrm{Y}$ chromosome, diploid complement of the ancient $\mathrm{X}$ chromosome and loss of the old Y chromosome would have an increased fitness. The new Y chromosome can be formed either through the emergence of a novel sex-determining gene, or alternatively through the transfer of the old $M S D$ gene.

situation sharply contrasts with the evolutionarily stable regulatory monarchies that have been established over more than 100 million years in birds and mammals. The diversity of mechanisms governing sex determination in fish might even be underestimated. For example, early genetic analyses have indicated that the great majority of salmonids have a system with male heterogamety, a priori suggesting a rather conserved sex determination mechanism. However, further analyses have demonstrated the existence of different $\mathrm{Y}$ chromosomes in at least four different salmonid species. 
There is no doubt that ongoing studies on stickleback, platyfish, tilapias and salmonids will uncover new regulatory dictators able to govern sex determination in fish and other vertebrates, and thousands of other fish species are awaiting their turn. Such analyses might also identify candidates able to replace the mammalian male-deter- mining gene $S R Y$ after its predicted fall [Marshall Graves, 2002]. Comparative analysis in fish will provide a unique panoramic view on the dynamics of sex determination and sex chromosome evolution, with particular emphasis on interactions with the environment and roles in the formation of species.

\section{References}

Adam D, Dimitrijevic N, Schartl M: Tumor suppression in Xiphophorus by an accidentally acquired promoter. Science 259:816819 (1993).

Allendorf FW, Gellman WA, Thorgaard GH: Sex-linkage of two enzyme loci in Oncorhyncus mykiss (rainbow trout). Heredity 72:498507 (1994).

-Aparicio S, Chapman J, Stupka E, Putnam N, Chia JM, et al: Whole-genome shotgun assembly and analysis of the genome of Fugu rubripes. Science 297:1301-1310 (2002).

-Artieri CG, Mitchell LA, Ng SH, Parisotto SE, Danzmann RG, et al: Identification of the sex-determining locus of Atlantic salmon (Salmo salar) on chromosome 2. Cytogenet Genome Res 112:152-159 (2006).

Bachtrog D: Accumulation of Spock and Worf, two novel non-LTR retrotransposons, on the neo-Y chromosome of Drosophila miranda. Mol Biol Evol 20:173-181 (2003).

Baroiller JF, D'Cotta H: Environment and sex determination in farmed fish. Comp Biochem Physiol C Toxicol Pharmacol 130:399409 (2001).

Baroiller JF, Chourrout D, Fostier A, Jalabert B: Temperature and sex chromosomes govern sex-ratios of the mouthbrooding cichlid fish Oreochromis niloticus. J Exp Zool 273:216223 (1995).

Black DA, Howell WM: The North American mosquitofish, Gambusia affinis: a unique case of sex chromosomes evolution. Copeia 1979:509-513 (1979).

Brunner B, Hornung U, Shan Z, Nanda I, Kondo $\mathrm{M}$, et al: Genomic organization and expression of the doublesex-related gene cluster in vertebrates and detection of putative regulatory regions for DMRT1. Genomics 77:8-17 (2001).

Campos-Ramos R, Harvey SC, Masabanda JS, Carrasco LA, Griffin DK, et al: Identification of putative sex chromosomes in the blue tilapia, Oreochromis aureus, through synaptonemal complex and FISH analysis. Genetica 111:143-153 (2001)

Carrasco LAP, Penman DJ, Bromage NR: Evidence for the presence of sex chromosomes in the Nile tilapia (Oreochromis niloticus) from synaptonemal complex analysis of XX, $\mathrm{XY}$ and YY genotypes. Aquaculture 173: 207-218 (1999).

Charlat S, Hurst GD, Mercot H: Evolutionary consequences of Wolbachia infections. Trends Genet 19:217-223 (2003).
Charlesworth B: Sex determination: primitive Y chromosomes in fish. Curr Biol 14:R745 R747 (2004)

Charlesworth B, Langley CH, Stephan W: The evolution of restricted recombination and the accumulation of repeated DNA sequences. Genetics 112:947-962 (1986).

Charlesworth B, Sniegowski P, Stephan W: The evolutionary dynamics of repetitive DNA in eukaryotes. Nature 371:215-220 (1994).

Charlesworth D, Charlesworth B, Marais G: Steps in the evolution of heteromorphic sex chromosomes. Heredity 95:118-128 (2005).

Cnaani A, Zilberman N, Tinman S, Hulata G, Ron M: Genome-scan analysis for quantitative trait loci in an F2 tilapia hybrid. Mol Genet Genomics 272:162-172 (2004).

Cui JZ, Shen XY, Gong QL, Yang GP, Gu QQ Identification of sex markers by cDNA-AFLP in Takifugu rubripes. Aquaculture 257:30-36 (2006).

Danzmann RG, Cairney M, Davidson WS, Ferguson MM, Gharbi K, et al: A comparative analysis of the rainbow trout genome with 2 other species of fish (Arctic charr and Atlantic salmon) within the tetraploid derivative Salmonidae family (subfamily: Salmoninae). Genome 48:1037-1051 (2005).

D'Cotta H, Fostier A, Guiguen Y, Govoroun M, Baroiller JF: Search for genes involved in the temperature-induced gonadal sex differentiation in the tilapia, Oreochromis niloticus. J Exp Zool 290:574-585 (2001).

Devlin R, Nagahama Y: Sex determination and sex differentiation in fish: an overview of genetic, physiological and environmental influences. Aquaculture 208:191-364 (2002).

Devlin RH, Biagi CA, Smailus DE: Genetic mapping of Y-chromosomal DNA markers in $\mathrm{Pa}$ cific salmon. Genetica 111:43-58 (2001).

Ezaz MT, Harvey SC, Boonphakdee C, Teale AJ, McAndrew BJ, Penman DJ: Isolation and physical mapping of sex-linked AFLP markers in Nile tilapia (Oreochromis niloticus L.). Mar Biotechnol (NY) 6:435-445 (2004).

Felip A, Fujiwara A, Young WP, Wheeler PA, Noakes M, et al: Polymorphism and differentiation of rainbow trout $\mathrm{Y}$ chromosomes. Genome 47:1105-1113 (2004).

Forbes SH, Knudsen KL, North TW, Allendorf FW: One of two growth hormone genes in coho salmon is sex-linked. Proc Natl Acad Sci USA 91:1628-1631 (1994).
Foresti F, Oliveira C, Galetti PM, Almeida-Toledo LF: Synaptonemal complex analysis in spermatocytes of tilapia Oreochromis niloticus (Pisces, Cichlidae). Genome 36:11241128 (1993).

Fricke H, Fricke S: Monogamy and sex change by aggressive dominance in coral reef fish. Nature 266:830-832 (1977).

Froschauer A, Körting C, Katagiri T, Aoki T, Asakawa $\mathrm{S}$, et al: Construction and initial analysis of bacterial artificial chromosome (BAC) contigs from the sex-determining region of the platyfish Xiphophorus maculatus. Gene 295:247-254 (2002).

Froschauer A, Braasch I, Volff JN: Fish genomes, comparative genomics and vertebrate evolution. Curr Genomics 7:43-57 (2006).

Furutani-Seiki M, Wittbrodt J: Medaka and zebrafish, an evolutionary twin study. Mech Dev 121:629-637 (2004).

Gharbi K, Gautier A, Danzmann RG, Gharbi S, Sakamoto T, et al: A linkage map for brown trout (Salmo trutta): chromosome homeologies and comparative genome organization with other salmonid fish. Genetics 172: 2405-2419 (2006).

Granato M, Nusslein-Volhard C: Fishing for genes controlling development. Curr Opin Genet Dev 6:461-468 (1996).

Graves JA: Sex chromosome specialization and degeneration in mammals. Cell 124:901-914 (2006).

Griffin DK, Harvey SC, Campos-Ramos R, Ayling LJ, Bromage NR, et al: Early origins of the $\mathrm{X}$ and $\mathrm{Y}$ chromosomes: lessons from tilapia. Cytogenet Genome Res 99:157-163 (2002).

Grützner F, Rens W, Tsend-Ayush E, El-Mogharbel N, O'Brien PC, et al: In the platypus a meiotic chain of ten sex chromosomes shares genes with the bird $\mathrm{Z}$ and mammal $\mathrm{X}$ chromosomes. Nature 432:913-917 (2004)

- Guo Y, Cheng H, Huang X, Gao S, Yu H, Zhou R: Gene structure, multiple alternative splicing, and expression in gonads of zebrafish Dmrt1. Biochem Biophys Res Commun 330: 950-957 (2005).

Gvozdev VA, Kogan GL, Usakin LA: The Y chromosome as a target for acquired and amplified genetic material in evolution. Bioessays 27:1256-1262 (2005).

Haaf T, Schmid M: An early stage of ZW/ZZ sex chromosome differentiation in Poecilia sphenops var. melanistica (Poeciliidae, Cyprinodontiformes). Chromosoma 89:37-41 (1984). 
Hamaguchi S, Toyazaki Y, Shinomiya A, Sakaizumi M: XX-XY sex-determination system in Oryzias luzonensis and O. mekongensis revealed by the sex ratio of the progeny of sexreversed fish. Zoolog Sci 21:1015-1018 (2004).

Harvey SC, Masabanda J, Carrasco LA, Bromage NR, Penman DJ, Griffin DK: Molecular-cytogenetic analysis reveals sequence differences between the sex chromosomes of Oreochromis niloticus: evidence for an early stage of sex-chromosome differentiation. Cytogenet Genome Res 97:76-80 (2002).

Harvey SC, Boonphakdee C, Campos-Ramos R, Ezaz MT, Griffin DK, et al: Analysis of repetitive DNA sequences in the sex chromosomes of Oreochromis niloticus. Cytogenet Genome Res 101:314-319 (2003).

He CL, Du JL, Wu GC, Lee YH, Sun LT, Chang CF: Differential Dmrt1 transcripts in gonads of the protandrous black porgy, Acanthopagrus schlegeli. Cytogenet Genome Res 101:309-313 (2003).

-Iturra P, Lam N, de la Fuente M, Vergara N, Medrano JF: Characterization of sex chromosomes in rainbow trout and coho salmon using fluorescence in situ hybridization (FISH). Genetica 111:125-131 (2001).

- Jaillon O, Aury JM, Brunet F, Petit JL, StangeThomann N, et al: Genome duplication in the teleost fish Tetraodon nigroviridis reveals the early vertebrate proto-karyotype. Nature 431:946-957 (2004).

Kallman KD: A new look at sex determination in poeciliid fishes, in Turner BJ (ed): Evolutionary Genetics of Fishes, pp 95-171 (Plenum Publishing Corporation, New York 1984).

-Katagiri T, Kidd C, Tomasino E, Davis JT, Wishon C, et al: A BAC-based physical map of the Nile tilapia genome. BMC Genomics 6:89 (2005).

Kazianis S, Nairn RS, Walter RB, Johnston DA, Kumar J, et al: The genetic map of Xiphophorus fishes represented by 24 multipoint linkage groups. Zebrafish 1:287-304 (2004).

Kirpichnikov VS: Genetic Basis of Fish Selection (Springer-Verlag, Berlin 1981).

-Kobayashi T, Matsuda M, Kajiura-Kobayashi H, Suzuki A, Saito N, et al: Two DM domain genes, $D M Y$ and $D M R T 1$, involved in testicular differentiation and development in the medaka, Oryzias latipes. Dev Dyn 231:518526 (2004).

Koehler MR, Dehm D, Guttenbach M, Nanda I, Haaf T, et al: Cytogenetics of the genus Leporinus (Pisces, Anostomidae). 1. Karyotype analysis, heterochromatin distribution and sex chromosomes. Chromosome Res 5:1222 (1997).

Kondo M, Nagao E, Mitani H, Shima A: Differences in recombination frequencies during female and male meioses of the sex chromosomes of the medaka, Oryzias latipes. Genet Res 78:23-30 (2001)

Kondo M, Nanda I, Hornung U, Asakawa S, Shimizu N, et al: Absence of the candidate male sex-determining gene $\operatorname{dmrt} 1 b(Y)$ of medaka from other fish species. Curr Biol 13:416420 (2003).
Kondo M, Nanda I, Hornung U, Schmid M, Schartl M: Evolutionary origin of the medaka Y chromosome. Curr Biol 14:1664-1669 (2004).

Kondo M, Hornung U, Nanda I, Imai S, Sasaki T, et al: Genomic organization of the sex-determining and adjacent regions of the sex chromosomes of medaka. Genome Res 16:815826 (2006).

Kumar S, Hedges SB: A molecular timescale for vertebrate evolution. Nature 392:917-920 (1998).

Larsson J, Meller VH: Dosage compensation, the origin and the afterlife of sex chromosomes. Chromosome Res 14:417-431 (2006).

Lee BY, Penman DJ, Kocher TD: Identification of a sex-determining region in Nile tilapia (Oreochromis niloticus) using bulked segregant analysis. Anim Genet 34:379-383 (2003).

Lee BY, Hulata G, Kocher TD: Two unlinked loci controlling the sex of blue tilapia (Oreochromis aureus). Heredity 92:543-549 (2004).

Lee BY, Lee WJ, Streelman JT, Carleton KL, Howe AE, et al: A second-generation genetic linkage map of tilapia (Oreochromis spp.). Genetics 170:237-244 (2005).

Li Y, Hill JA, Yue G, Chen F, Orban L: Extensive search does not identify genomic sex marker in Tetraodon nigroviridis. J Fish Biol 61: 1314-1317 (2002).

Lindholm A, Breden F: Sex chromosomes and sexual selection in poeciliid fishes. Am Nat 160:S214-S224 (2002).

Mair GC, Scott A, Penman DJ, Beardmore JA, Skibinski DOF: Sex determination in the genus Oreochromis I: Sex reversal, gynogenesis, and triploidy in O. niloticus L. Theor Appl Genet 82:144-152 (1991).

Mank JE, Promislow DEL, Avise JC: Evolution of alternative sex-determining mechanisms in teleost fishes. Biol J Linn Soc 87:83-93 (2006).

Marchand O, Govoroun M, D'Cotta H, McMeel O, Lareyre J, et al: DMRT1 expression during gonadal differentiation and spermatogenesis in the rainbow trout, Oncorhynchus mykiss. Biochim Biophys Acta 1493:180-187 (2000).

Marshall Graves JA: The rise and fall of SRY. Trends Genet 18:259-264 (2002).

Marshall Graves JA, Shetty S: Sex from W to Z: evolution of vertebrate sex chromosomes and sex determining genes. J Exp Zool 290: 449-462 (2001).

Matsuda M: Sex determination in the teleost medaka, Oryzias latipes. Annu Rev Genet 39: 293-307 (2005).

Matsuda M, Matsuda C, Hamaguchi S, Sakaizumi M: Identification of the sex chromosomes of the medaka, Oryzias latipes, by fluorescence in situ hybridization. Cytogenet Cell Genet 82:257-262 (1998).

Matsuda M, Sotoyama S, Hamaguchi S, Sakaizumi M: Male-specific restriction of recombination frequency in the sex chromosomes of the medaka, Oryzias latipes. Genet Res 73: 225-231 (1999).
Matsuda M, Nagahama Y, Shinomiya A, Sato T, Matsuda C, et al: DMY is a Y-specific DMdomain gene required for male development in the medaka fish. Nature 417:559-563 (2002)

Matsuda M, Sato T, Toyazaki Y, Nagahama Y, Hamaguchi S, Sakaizumi M: Oryzias curvinotus has DMY, a gene that is required for male development in the medaka, O. latipes. Zoolog Sci 20:159-161 (2003).

McElreavey K, Ravel C, Chantot-Bastaraud S, Siffroi JP: Y chromosome variants and male reproductive function. Int J Androl 29:298306 (2006).

Meierjohann S, Schartl M: From Mendelian to molecular genetics: the Xiphophorus melanoma model. Trends Genet 22:654-661 (2006).

Meierjohann S, Schartl M, Volff JN: Genetic, biochemical and evolutionary facets of $X m r k$-induced melanoma formation in the fish Xiphophorus. Comp Biochem Physiol C Toxicol Pharmacol 138:281-289 (2004).

Mittwoch U: Sex determination in mythology and history. Arq Bras Endocrinol Metabol 49:7-13 (2005)

Muller HJ: A gene for the fourth chromosome of Drosophila. J Exp Zool 17:325-336 (1914).

Muller HJ: Genetic variability, twin hybrids and constant hybrids, in the case of balanced lethal factors. Genetics 3:422-499 (1918).

Nanda I, Shan Z, Schartl M, Burt DW, Koehler M, et al: 300 million years of conserved synteny between chicken $\mathrm{Z}$ and human chromosome 9. Nat Genet 21:258-259 (1999).

-Nanda I, Volff JN, Weis S, Korting C, Froschauer A, et al: Amplification of a long terminal repeat-like element on the Y chromosome of the platyfish, Xiphophorus maculatus. Chromosoma 109:173-180 (2000).

Nanda I, Kondo M, Hornung U, Asakawa S, Winkler C, et al: A duplicated copy of DMRT1 in the sex-determining region of the Y chromosome of the medaka, Oryzias latipes. Proc Natl Acad Sci USA 99:1177811783 (2002).

Nanda I, Hornung U, Kondo M, Schmid M, Schartl M: Common spontaneous sex-reversed XX males of the medaka Oryzias latipes. Genetics 163:245-251 (2003).

Naruse K, Hori H, Shimizu N, Kohara Y, Takeda $\mathrm{H}$ : Medaka genomics: a bridge between mutant phenotype and gene function. Mech Dev 121:619-628 (2004).

$\mathrm{Ng} \mathrm{SH}$, Artieri CG, Bosdet IE, Chiu R, Danzmann RG, et al: A physical map of the genome of Atlantic salmon, Salmo salar. Genomics 86:396-404 (2005)

Ohno S: Sex Chromosomes and Sex-Linked Genes (Springer, Berlin 1967).

Otake H, Shinomiya A, Matsuda M, Hamaguchi S, Sakaizumi M: Wild-derived XY sex-reversal mutants in the medaka, Oryzias latipes. Genetics 173:2083-2090 (2006).

Peichel CL: Fishing for the secrets of vertebrate evolution in threespine sticklebacks. Dev Dyn 234:815-823 (2005). 
- Peichel CL, Ross JA, Matson CK, Dickson M, Grimwood J, et al: The master sex-determination locus in threespine sticklebacks is on a nascent $Y$ chromosome. Curr Biol 14:14161424 (2004).

- Phillips R, Rab P: Chromosome evolution in the Salmonidae (Pisces): an update. Biol Rev Camb Philos Soc 76:1-25 (2001).

- Phillips RB, Konkol NR, Reed KM, Stein JD: Chromosome painting supports lack of homology among sex chromosomes in $\mathrm{On}$ corhynchus, Salmo, and Salvelinus (Salmonidae). Genetica 111:119-123 (2001).

- Phillips RB, Morasch MR, Park LK, Naish KA, Devlin RH: Identification of the sex chromosome pair in coho salmon (Oncorhynchus kisutch): lack of conservation of the sex linkage group with chinook salmon (Oncorhynchus tshawytscha). Cytogenet Genome Res 111:166-170 (2005).

Pryde FE, Gorham HC, Louis EJ: Chromosome ends: all the same under their caps. Curr Opin Genet Dev 7:822-828 (1997).

Quillet E, Aubard G, Queau I: Mutation in a sexdetermining gene in rainbow trout: detection and genetic analysis. J Hered 93:91-99 (2002).

- Raymond CS, Shamu CE, Shen MM, Seifert KJ, Hirsch B, et al: Evidence for evolutionary conservation of sex-determining genes. Nature 391:691-695 (1998).

Reed KM, Bohlander SK, Phillips RB: Microdissection of the Y chromosome and fluorescence in situ hybridization analysis of the sex chromosomes of lake trout, Salvelinus namaycush. Chromosome Res 3:221-226 (1995).

Roest Crollius H, Weissenbach J: Fish genomics and biology. Genome Res 15:1675-1682 (2005).

-Rozen S, Skaletsky H, Marszalek JD, Minx PJ, Cordum HS, et al: Abundant gene conversion between arms of palindromes in human and ape Y chromosomes. Nature 423:873876 (2003).

- Samonte RV, Eichler EE: Segmental duplications and the evolution of the primate genome. Nat Rev Genet 3:65-72 (2002).

Sato T, Endo T, Yamahira K, Hamaguchi S, Sakaizumi M: Induction of female-to-male sex reversal by high temperature treatment in medaka, Oryzias latipes. Zool Sci 22:985988 (2005).

-Schartl M: Sex chromosome evolution in nonmammalian vertebrates. Curr Opin Genet Dev 14:634-641 (2004a).

Schartl M: A comparative view on sex determination in medaka. Mech Dev 121:639-645 (2004b).

Schartl M, Hornung U, Gutbrod H, Volff JN, Wittbrodt J: Melanoma loss-of-function mutants in Xiphophorus caused by Xmrk-oncogene deletion and gene disruption by a transposable element. Genetics 153:1385-1394 (1999).
Schultheis C, Zhou Q, Froschauer A, Nanda I, Selz Y, et al: Molecular analysis of the sexdetermining region of the platyfish Xiphophorus maculatus. Zebrafish 3:295-305 (2006).

Shan Z, Nanda I, Wang Y, Schmid M, Vortkamp A, Haaf T: Sex-specific expression of an evolutionarily conserved male regulatory gene, DMRT1, in birds. Cytogenet Cell Genet 89: 252-257 (2000).

Shinomiya A, Matsuda M, Nagahama Y, Hamaguchi S, Sakaizumi M: A strain having a ZZ/ ZW sex determination system derived from a naturally occurring recessive mutation in the medaka, Oryzias latipes. Zoolog Sci 19: 1496-1500 (2002).

Shinomiya A, Ohmori T, Hamaguchi S, Sakaizumi M: Mapping of a factor that causes male sex-reversal of XX medaka. Zoolog Sci 20:1612-1615 (2003).

Shinomiya A, Otake H, Togashi K, Hamaguchi S, Sakaizumi M: Field survey of sex-reversals in the medaka, Oryzias latipes: genotypic sexing of wild populations. Zoolog Sci 21: 613-619 (2004).

Skaletsky H, Kuroda-Kawaguchi T, Minx PJ, Cordum HS, Hillier L, et al: The male-specific region of the human $Y$ chromosome is a mosaic of discrete sequence classes. Nature 423:825-837 (2003).

Smith CA, Sinclair AH: Sex determination: insights from the chicken. Bioessays 26:120132 (2004).

Smith CA, McClive PJ, Western PS, Reed KJ, Sinclair AH: Conservation of a sex-determining gene. Nature 402:601-602 (1999).

-Stein J, Phillips RB, Devlin RH: Identification of the $\mathrm{Y}$ chromosome in chinook salmon (Oncorhynchus tshawytscha). Cytogenet Cell Genet 92:108-110 (2001).

Steinemann S, Steinemann M: Y chromosomes: born to be destroyed. Bioessays 27:10761083 (2005).

Steinke D, Salzburger W, Meyer A: Novel relationships among ten fish model species revealed based on a phylogenomic analysis using ESTs. J Mol Evol 62:772-784 (2006).

- Thorgaard GH: Heteromorphic sex chromosomes in male rainbow trout. Science 196: 900-902 (1977).

Traut W, Winking H: Meiotic chromosomes and stages of sex chromosome evolution in fish: zebrafish, platyfish and guppy. Chromosome Res 9:659-672 (2001).

Veith AM, Froschauer A, Korting C, Nanda I, Hanel R, et al: Cloning of the $d m r t 1$ gene of Xiphophorus maculatus: dmY/dmrt1Y is not the master sex-determining gene in the platyfish. Gene 317:59-66 (2003).

Veith AM, Schäfer M, Klüver N, Schmidt C, Schultheis C, et al: Tissue-specific expression of dmrt genes in embryos and adults of the platyfish Xiphophorus maculatus. Zebrafish 3:321-332 (2006).

Volff JN: Genome evolution and biodiversity in teleost fish. Heredity 94:280-294 (2005).
Volff JN, Schartl M: Variability of genetic sex determination in poeciliid fishes. Genetica 111: 101-110 (2001)

Volff JN, Schartl M: Sex determination and sex chromosome evolution in the medaka, Ory zias latipes, and the platyfish, Xiphophorus maculatus. Cytogenet Genome Res 99:170177 (2002).

-Volff JN, Bouneau L, Ozouf-Costaz C, Fischer C: Diversity of retrotransposable elements in compact pufferfish genomes. Trends Genet 19:674-678 (2003a).

Volff JN, Kondo M, Schartl M: Medaka $d m Y$ / $d m r t 1 Y$ is not the universal primary sex-determining gene in fish. Trends Genet 19: 196-199 (2003b).

Volff JN, Körting C, Froschauer A, Zhou Q, Wilde B, et al: The Xmrk oncogene can escape nonfunctionalization in a highly unstable subtelomeric region of the genome of the fish Xiphophorus. Genomics 82:470-479 (2003c).

Volff JN, Zarkower D, Bardwell VJ, Schartl M: Evolutionary dynamics of the DM domain gene family in metazoans. J Mol Evol 57: S241-S249 (2003d).

Winkler C, Hornung U, Kondo M, Neuner C, Duschl J, et al: Developmentally regulated and non-sex-specific expression of autosomal dmrt genes in embryos of the Medaka fish (Oryzias latipes). Mech Dev 121:9971005 (2004).

Wittbrodt J, Adam D, Malitschek B, Maueler W, Raulf F, et al: Novel putative receptor tyrosine kinase encoded by the melanoma-inducing Tu locus in Xiphophorus. Nature 341: 415-421 (1989).

Wittbrodt J, Shima A, Schartl M: Medaka - a model organism from the Far East. Nat Rev Genet 3:53-64 (2002).

Woolcock B, Kazianis S, Lucito R, Walter RB, Kallman KD, et al: Allele-specific marker generation and linkage mapping on the $\mathrm{Xi}$ phophorus sex chromosomes. Zebrafish 3: 23-37 (2006).

Woram RA, Gharbi K, Sakamoto T, Hoyheim B, Holm LE, et al: Comparative genome analysis of the primary sex-determining locus in salmonid fishes. Genome Res 13:272-280 (2003).

Yamamoto T: Progeny of artificially induced sex-reversals of male genotype (XY) in the medaka (Oryzias latipes) with special reference to YY-male. Genetics 40:406-419 (1955).

Zarkower D: Establishing sexual dimorphism: conservation amidst diversity? Nat Rev Genet 2:175-185 (2001).

Zhang J: Evolution of $D M Y$, a newly emergent male sex-determination gene of medaka fish. Genetics 166:1887-1895 (2004).

Zhou Q, Froschauer A, Schultheis C, Schmidt C, Bienert $\mathrm{P}$, et al: Helitron transposons on the sex chromosomes of the platyfish Xiphophorus maculatus and their evolution in animal genomes. Zebrafish 3:39-52 (2006). 